\title{
Animating Folktales: An Analysis of Animation Movies based on Folktales of three different Indian Languages
}

\section{Maya Bhowmick ${ }^{1}$}

${ }^{1}$ Student, Department of Communication and Journalism, Gauhati University, Guwahati, India.

Mail Id: mayab.bhowmick@gmail.com

\author{
Ankuran Dutta ${ }^{2}$ \\ ${ }^{2}$ Associate Professor and Head, Department of Communication and Journalism, Gauhati University, \\ Guwahati, India. \\ Mail Id: adutta@gauhati.ac.in | Orchid ID: 0000-0002-0637-9846
}

\begin{abstract}
Folktales are the oldest and traditional means of communication having remained a powerful means of communication over the years. Since its inception this method of storytelling and communicating has changed its medium of transmission but not its manner of storytelling. For ages, oral tradition has been a medium of transmission of these stories and culture but with modernization, the medium changed to print, electronic, and now digital media. These folktales do not represent mere stories; but communicate the varied culture, tradition, rituals, history and much other vital information reflecting the timeline of various communities. Serving as an active agent of both information and entertainment at the community level for so many years today, there arises an immediate need to preserve this form of storytelling - Folktales, especially in the context of its presentation has witnessed a change in recent times. Animation being the latest medium of entertainment, folktales can also be narrated in the form of animation that will also help preserve the stories in animated form for future generations. By doing so, folktales can be pushed beyond the boundaries of the community level and can be prevailed in the global platform to benefit the entire human race. Several communities across the globe have converted their folktales into animated movies to acquire the wider reach of audiences globally. This also helps to popularize the old traditions of these communities so that the newer generations can understand its significance in the present-day context of digital platforms. Moreover, extinguishing the line of the geographical divide, it ties people living across the world together through its common thread of lesson learning folktales.
\end{abstract}

Keywords: Folktales, Animation Movies, Animated Folktales, Hindi, Bengali, Assamese, Digital Media, YouTube

64

Litinfinite Journal is Indexed By MLA Directory Of Periodicals \& MLA International Bibliography, EBSCO, ProQuest, SCILIT, Ulrichsweb \& Ulrich's Periodicals Directory, ICI World Of Journals, J-Gate, JISC-Sherpa Romeo, DRJI, EuroPub \& Other Major Indexing Services. (This Open Access article is published under a Creative Commons Attribution Non-Commercial 4.0 International License.) 


\section{Introduction}

Dan Ben Amos a folklorist, defines folklore as, "Artistic communication in small groups". At the beginning of the $19^{\text {th }}$ century 'Folklore' got a proper recognition, prior to which it was just a household culture or tradition. The Germans Jacob Grimm and Williams Grimm were the first to look into the study of folklore, it is from there that the idea spread to different nations but the term 'folklore' was first used by William John Thomas (an English scholar) in 1846. Thus, this new term was used in the new field of study, with the term many folklorists went into studying different areas of the subject. According to Dorson (1972)1, folklore is classified into the following 4 broad categories namely oral literature, material culture, folk custom, and folk performing art. The oral literature consists of all forms of oral traditions like hymns, stories, songs, phrases, poetry, rhymes, proverbs, riddles. Though it is not necessary for all the oral folk traditions to be verbal some may be in form of hollers, cries, laments, chants, or other sounds.

In the communication studies, all these folklore forms are popularly known as folk media or traditional folk media (Dutta, 2004). The folk media in India is further classified into 8 broad categories, by Parmar (1975) as traditional folk theatre forms (example: Bhaona, Jatra, Bhari-gaan), puppetry (example: Putul Nach or Putala Nas, Kath Putli), folk dances (example: Chau, Bihu, Bhangra, Garba, Ghumar), festivals (example: Junbeel Mela, Pushkar Mela, Kumbh Mela), traditional youth clubs (example: Yo, Morang, Deka), traditional designs (example: Swastika, Lakshmi footprints, Zig Zag patterns of Nagas), sounds, signals, and speeches (example: Drum Beats, Uludhwani) and oral literature cum musical forms (example: Baul, Bhatiali, Powada, Lavani) ${ }^{2}$.

\section{Review of literature}

Every dynasty has its culture and habits beautifully narrated through these stories. It states clearly that the oral culture was initiated to create a relation between the humans and nature (which was then considered to be super powerful) than gradually with the advancement of time, the storyline changed from nature to gods and myths delivering stories with values to the people. The instances

\footnotetext{
${ }^{1}$ Richard M. Dorson in his book Folklore and Folklife an Introduction, discusses in detail about the branches of folklore and its uses in day to day life.

${ }^{2}$ Baul is a form of folk song in Bengal comprising both parts of present Bangladesh and West Bengal; Bhatiali is also a form of folk song in Bengal, which was mostly sung by the boatman's of Bengal; Lavani is also a form of folk song and dance of Maharashtra; Powada is a form of folk poetry in Maharashtra.
} 
of Greek mythology and Chinese mythology explains how nature was part of a plot in stories (the stories of the union of earth and sky). The art of storytelling dates back to the Neolithic times, earlier the people used to gather around the fire in the evening and eat, dance, and share their stories, as one would end their story the other would start their story and the rest would listen. While initially, the topics were narrow but with the advent of time the topics covered a large area and became vast (Huang, 2018).

According to Penjore (2005), Bhutanese folktales has clear indication of contribution in different aspects of the society especially children related matters. Underprivileged children got their knowledge from these folktales as they could not afford to get the schools unlike those from the royal families. It also explains the importance of sharing folktales with the children as only sending them to school was not enough for their all-round development as educational institutions with give them curriculum based knowledge and impart them theoretical knowledge while the moral values, local history, and learnings from the experiences can be imparted only through folktales. It also indicates that the primary learning of every child starts from home where the members impart them through folktales. Their folktales have a wide range of stories from dynasties, monks, rich people, kings, working people, and poor. These stories have a long history as they have stories of age-long kingdoms and dynasties and the tales of their bravery and wars. Such stories have a life lesson for the children facing different challenges. The policy recommendations of Bhutan in regard to folktales transmission through various media are also described.

Another study looks into the Patachitra art of Bengal ${ }^{3}$, the famous art culture which captured the oral literature through its images and paintings. During those days the oral literature was not documented through writings, thus the patachitra art became an essential part of archiving the oral tales. The tales of migration, socio-cultural evolution, and the trading stories are depicted through this art. The reprinted version of patachitra helps in the documentation of cultures and society in an archaeological and anthropological survey. Thus, patachitra first marked the preservation of oral culture in the eastern parts of India (Bajpai, 2015).

In a project titled "A Model for Animation of Yorùbá Folktale Narratives" a group of scholars have been working on the Yorùbá folktale narratives and trying to design a model for animation. A paper based on the project argues that animation as a multimedia element has drawn the

\footnotetext{
${ }^{3}$ Patachitra is a form of folk art in Bengal, where the evolution over years of the community has taken the form of art. The folk art recites the various stories of the community.
} 
attention of both young and old, and has shown to be a veritable tool for both formal and informal education used in making sense of place, culture and heritage serving as a medium for fostering the spirit of reading among children and younger adults, promoting socio-cultural norms, and values, preserving and conserving our cultural heritage and revitalization of our indigenous languages (Aládé, et al. 113). Another important work is based on how to develop cartoons of local folktales that will be of huge benefits to Nigerians. The activities were divided into 5 stages; analysis, design, development, implementation and evaluation which involved various processes and use of various specialized software and hardware (Ibrahim, et al. 19). Another similar kind of study, whose objective is to develop a digital animation film using Yoruba folktale narrative as a case study with a view to providing a framework to enhance the production of animated folktales as well as supporting Africa's rich cultural heritage, using relevant technology resources (Mayowa, 47). But all these three studies are conducted from the computer science background with technical perspective, not from the viewpoint of animation storytelling narrative of folktales.

From the literature studied during this research, we got to know about the developments and history of folktales of various countries, their purposes, and the roadmap of taking their respective traditional folktales to the present-day generation. But there seems to be a lack of study in the folktales-based animation moves as a whole and also an Indian perspective. The deeper study on Indian folktales and its outreach will give a detailed insight into our traditional folktales, how far have they developed in comparison with the different regions of India.

\section{Methodology}

To conduct the research, literature related to the history of folktales and animations, the importance of animations in popularizing and preserving the folktales are studied. Content analysis was applied in this study to analyze each animation individually. A qualitative approach was undertaken to analyze the stories based on the five analyzing parameters such as- a) the Quality of Animation, b) Dialogues, c) Music, d) Characters And e) Storyline.

\section{Selection procedure:}

Since the list of Hindi animation movies was more in quantity than the other two languages, the most viewed animations from each collection were selected for the research from a YouTube analytic. Each of these animations is analyzed based on the five mentioned criteria, so that findings remain impartial for each language. A total of 30 animation movies were selected based on the number of views, of which was 10 movies of each of three languages. 


\section{Types of sources:}

The data used for this research both literature and video are taken from secondary sources, each data is taken from the public domain with copy left policies and there is no license issue in these sources. The literature and videos are used by fair means. Due to the current prevalent situation of the COVID-19 pandemic, outdoor survey or personal interviews to assess the impact of these videos were not feasible, so the research is carried out with all the help taken from secondary sources.

\section{Conceptual Framework}

The culture and history of a particular group of people or society, which are transmitted orally throughout the generations, are folklore. Folklores are passed on through two important agents firstly the active narrator and secondly the passive listener, wherewith time the passive listener turns into the narrator after a certain point. Every society has its own history of kings, unsung heroes, dynasties, in a manner that the history is passed on from one generation to another. Folklore has various categories of folktales, songs, dance, riddles, etc. Folktale is a category of oral literature or verbal art under folklores; different countries across the globe have their different outlook on folklores. Folklores were meant for all people in the society before the division of society into castes, after the division, the folklores became a part of the lower or labour class people of the society. As described by many western folklorists the folklore is of peasants, the poor, labour and so on. But we find the evidence of the existence of folklore since the primitive ages, when men started to settle down and habitation started, we find the traces from the stone age. These cultures are long ages old; it holds its vast history folklore has in it the transition of the group from its very beginning; the stories are interpreted and reinterpreted in various ways throughout the years (Propp, 1984).

Folktales and animation both are vital for the society; here animations help the folktales get popular through its medium, since animation attracts the children a lot. Digital animations comparatively being a new media can be reached to many at the same time. When the children watch any animation, they learn a lot from their multimedia experiences, especially when they watch animations of other more popular cultures they tend to follow and get ignorant of their own culture. So, when the animation movies based on folktales are made of their own regional folk stories and depict their culture, the children get to know more about the culture and inculcate those cultures within them. Many regions despite having rich folk culture but due to lack of technological advancements fail to match up with the present-day world and lack behind in 
putting up their stories to their children. Here the primary reason for regional folktale animation is to pass on the stories to the children and then secondarily, to put up for the global audiences (Ibrahim, 2013).

\section{Discussion and findings:}

Throughout the analysis, a vast difference can be seen in the animated folktales in the selected languages.

\section{The Hindi animated folktales}

Hindi animated folktales are huge in number, most of the folktales are found in the animated form. Their stories are well structured and presented, we can find a variety of options for Hindi folktales, we can find proper series of each folktale which are well preserved in the digital platform. The very first thing that attracts the audiences in Hindi animated folktales is the quality of the animation, which is of very high resolution, technically perfect and professionally made. Each and every story is easily found in different digital content sharing platforms, the stories range from epic Ramayana, Mahabharata to Tenali Rama, Akbar Birbal and so on. The languages used are easily understandable, the music and sound effects, visual effects everything adds on to the quality of the animation. There are various channels where we can find the same folktales, so it gives an option to the audiences to select the better ones in terms of quality and presentation; it also creates a scope of healthy competition among the creators to create quality content for the audiences. A great level of expertise and professionalism is used to make these animations, which results in a standardized content. Based on the quality of the animations, it is also clearly visible the huge popularity of the Hindi animated folktales compared to the other animation movies of the regional languages. The animations have the right tone and amount of narration and dialogues of the characters, which helps the audiences in a better understanding of the plots. The movement of the characters and the transition of the scenes are smooth and spontaneous making the animation worth watching.

\section{The Assamese animated folktales}

Assamese animated folktales have a very limited number of folktales in the digital platform rather than a handful of them. The quality of the animations is very meagre as it is just an amalgamation of images inserted into a video, there are very few which can be considered as a proper video. Except, the animated movies like 'Latkan', the image quality of many of them is very poor due to a lack of professional skills and techniques. The plots are not well structured and presented in a 
modest form, which fails to attract more audiences and thus fail to gain popularity. While searching the animation movies based on folktales in the Assamese, the results were very limited, there was no such dedicated YouTube channel for Assamese folktales animation. The videos were from random channels where they cover folktales in occasional times. The stories are mostly narrated rather than smooth dialogue delivery between the characters. One of the major drawbacks is the picture quality, the images get blurred most of the time also the movement of the characters is not smooth. The transition of scenes breaks down which causes hindrances while watching the animation. The very famous folktales are hard to find in animated form. The tone of the narration is very monotonous, which makes it all the harder to concentrate throughout the story. The scenes are plotted and presented in some stories, while in others it is confusing. The Assamese animated folktales fail to create a target audience through their animations due to a lack of involvement and techniques. However, there are many video films made on the folktales of Assam, most particularly the folktales of 'Burhi Air Xadhu' are filmed with the real characters but not in animated form.

\section{Bengali animated folktales:}

The Bengali animated folktales somewhat stand in a better position if compared to the other regional lingual animations. A long list of results come out when searched for Bengali animated folktales, there are various stories covered but not all stories are covered through animations some important stories are definitely missing. There are very few dedicated channels for folktales, the professional and skill level is moderate in some stories, higher in some, and poor in some selected stories. The quality of the video is decent, it does not get blurred and images do not get glitches. There are proper distinct narrations and dialogue delivery throughout the stories. The music, sound effects and visual effects are found in most of the stories, but some stories are left behind in terms of quality and presentation. The animations are popular enough while some have a very high number of views, rest of the stories have a moderate number of views in comparison to the Hindi animation but higher popularity if compared to Assamese animated folktales. A variety of the same story is not available, there are single results for every folktale mostly unlike the Hindi folktales where we can find the same story in different channels presented and enunciated differently. Stories are available in series form. The stories are well sequenced; the quality of images is comparatively satisfactory but that of much higher resolution. The story runs smoothly and spontaneously, the lively characters also add to the attractions of the audiences.

\section{Findings:}


After the thorough content analysis of the animations on folktales of three different languages (Hindi, Bengali, Assamese), we can say that there is a huge difference in the making of animations in each language. The quality makes a huge difference in each animation. While the story can match at certain points, as folktales in different places can have same stories with little variations based on the regions. Through folktales we can understand the people and their history, the stories reflect the society. The stories impart moral lessons to the children or the audiences in the form of entertainment. The same story interpreted in different languages differs from one another in some way or the other. As we all know the children these days mostly watch Hindi animations rather than their own regional animations, through the observations of this study we can state the reasons or drawbacks of the regional animations due to which they fail to compete with the popularity of the animations in Hindi.

\section{Drawbacks:}

Some of the major drawbacks that are necessary to be highlighted. There is a wide gap in the views of the animations in different languages, due to the various factors. The quality of the video deteriorates when it goes to regional videos due to a lack of technological advancements and software and also a lack of professional expertise and skills. The technologies used in the Hindi animated folktales are much advanced that can meet the global standard while the regional animations fail to achieve that despite having great stories. The animations in Hindi are well created; every story is almost created through animations and is well maintained and preserved, whereas the regional animations are neither well maintained nor created that often if compared to the Hindi animations. The Hindi animations are easily available with lots of options for the same story, which is a major missing in the regional animations, as most of them are not available and people are left with no options but as to watch what is available. Both the regional languages animation has misleading titles and gives out the wrong information which directly shows the interest level of the people in preserving the stories. There is a dedicated channel or source to find Hindi animations, while the regional animations fail in doing so. There is no such dedicated channel for animations; hence the wonderful stories are left out.

Considering only the views and of the analyzed stories, we can see a major difference, firstly in the number of views and secondly the stories. While there are folktales from various collections in Hindi, there are stories from only one collection in Bengali while in Assamese the stories are also mostly from one collection. The folktales in Hindi have views in crores, lakhs, and thousands based on the popularity of the series, the Bengali folktales have views in crores while the 
Assamese folktales have comparatively much fewer views than the other two languages. It is of course, because of the population of West Bengal, Tripura, and Barak Valley of Assam along with Bangladesh, Bengali stories are seen most. But they are still less in number in comparison to the animated folktales in Hindi.

\section{Conclusion}

Unlike other countries, India has a huge collection of folktales that interlinks with the main classical stories, with the vast geographical expansion and each region has its own stories or different versions of stories in different states. As the traditional way of knowing the story was through oral means but in the present scenario, it has shifted to digital forms like animation due to various circumstances. To cope up with the present time of technological advancements and change in taste of audiences, the age-old stories can be preserved and made popular again through the use of animations. This audiovisual way attracts the present-day audiences and gives them the knowledge and information in a more interesting way.

The study shows the comparison between the animations of three different languages (Hindi, Bengali, and Assamese), while Bengali and Assamese being the regional folktales lack behind in all aspects of the Hindi animations. The regional stories are not transformed into animation form. As the children watch the other folktales they learn about the cultures of other region, but they fail to know their own society and its culture. One becomes ignorant to one's own culture and history and follows the other, so when the present generation becomes ignorant towards their own culture, the culture is set to be extinct.

The two most essential reasons to remake the regional folktales in digital form like animation are to prevent the culture and history of the region from getting extinct and to preserve the stories for a longer time. These regions despite having rich folk culture are hard to find in the digital form, there are very few in fact very limited tales made in digital form on the other hand the Hindi animations are huge in number and popular too. Every collection of Hindi folktales is almost available in digital form, while the ratio of regional folktales falls down to less than half. Due to lack of availability, the great stories are also dying, which shows us the importance of making the animations from the folktales, to reach more audiences and keep the culture alive.

(Acknowledgement: Dr Anupa Lahkar Goswami, Assistant Professor, Gauhati University and Mr Raja Das, Research Associate, Dr Anamika Ray Memorial Trust) 


\section{References}

Alade et al, S. M., et al. "A model for animation of Yoruba Folktale Narratives." African Journal of Computing \& ICT 8.2 (2015): 113-120. Web. 15 Dec. 2020.

$<$ https://www.researchgate.net/publication/308352527_A_Model_for_Animation_of_Yoruba_Folktale _Narratives>;

Assamese song and culture. "Kon aru mon Assamese animated film." YouTube. N.p., 12 Nov. 2017. Web. 16 Dec. 2020. <https://youtu.be/B0bPh2gjlvU>;.

Axomiya e sahitya. "Burhi aair hadhu mekuri jiyek hadhu by laxminath bezboruah." YouTube. N.p., 15 May 2019. Web. 16 Dec. 2020. <https:/ / youtu.be/MQL_t47oqqg>;.

Bajpai, Lopamudra M. "Myths and folktales in the Patachitra art of Bengal : Tradition and modernity." Chitrolekha international magazine on art and design 1 Nov. 2015: 173. Web. 15 Dec. 2020.

<http://chitrolekha.com/myths-and-folktales-patachitra/>;.

Boruah, Sanchayita. "Dhorakauri aru tipuchi sorae buriya aair hadhu Assamese story by laxminath bezbaruah." YouTube. N.p., 21 July 2020. Web. 16 Dec. 2020. <https://youtu.be/yBQKiK0tRNE>;.

Chutia, Pranjal. "Lotkan Assamese funny video." YouTube. N.p., 28 Mar. 2018. Web. 16 Dec. 2020. $<$ https://youtu.be/c9NavSqzES0>;

Dawsen tv bengali stories. "Thakurmar jhuli Bitu bhoot bengali stories for children. Thakurmar jhuli cartoon." YouTube. N.p., 14 Oct. 2017. Web. 16 Dec. 2020. <https:/ / youtu.be/6POA5cQhMNg>;.

Dawsen tv bengali stories. "Thakurmar jhuli hela o phela bengali stories for children. Thakurmar jhuli cartoon." YouTube. N.p., 5 Nov. 2018. Web. 16 Dec. 2020. <https://youtu.be/6POA5cQhMNg>;.

Dawsen tv bengali stories. "Thakurmar jhuli teko bau bengali stories for children. Bengali moral stories for kids." YouTube. N.p., 18 Oct. 2017. Web. 16 Dec. 2020. <https://youtu.be/1KMJ6NFDS10>;

Dorson, Richard M. Folklore and folklife An introduction. Chicago: The university of Chicago Press Chicago and London, 1972. Print.

Huang, Yonglin. "Popular literature, elite literature and Folk literature." Narrative of Chinese and Western popular fiction. Germany: Germany: Springer Verlag GmbH Germany, 2018. 23-44. Web. 15 Dec. 2020. <https:/ /link.springer.com/ book/10.1007/978-3-662-57575-8>;.

Ibrahim, et al. "3D computer animation for a Yoruba Native Folktale." International Journal of Computer Graphics \& Animation 5.3 (2018): 19-27. Web. 14 Dec. 2020.

$<$ https://www.researchgate.net/publication/281004740_3D-

Computer_Animation_For_a_Yoruba_Native_Folktale>;

Ibrahim, et al. "A proposed model for animation of Malay folktales for children." Information Systems International Conference. Malaysia. 4 Dec. 2013. Web. 15 Dec. 2020.

<https://www.researchgate.net/publication/308352527_A_Model_for_Animation_of_Yoruba_Folktale _Narratives>;

Litinfinite Journal is Indexed By MLA Directory Of Periodicals \& MLA International Bibliography, EBSCO, ProQuest, SCILIT, Ulrichsweb \& Ulrich's Periodicals Directory, ICI World Of Journals, J-Gate, JISC-Sherpa Romeo, DRJI, EuroPub \& Other Major Indexing Services. (This Open Access article is published under a Creative Commons Attribution Non-Commercial 4.0 International License.) 
Kids rhymes- nursery rhymes and stories. "Thakurmar jhuli Sona Rupa o daine bangla cartoons.

Thakurmar jhuli full episode." YouTube. N.p., 29 Mar. 2018. Web. 16 Dec. 2020.

<https://youtu.be/npW33f2Zsr0>;

Magicbox Animation. "Hitopadesha tales in full movie HD. Moral stories in hindi." YouTube. N.p., 18 Nov. 2014. Web. 16 Dec. 2020. <https:/ / youtu.be/wU3ogN9qJts>;.

Magicbox Hindi. "Akshayapatra- Mahabharath in Hindi. Epic stories in hindi." YouTube. N.p., 19 Aug. 2019. Web. 16 Dec. 2020. <https://youtu.be/DW-hogRAaBQ>;.

Magicbox Hindi. "Foolish disciple - Jataka tales for kids. Hindi Stories for kids. Magic box Hindi." YouTube. N.p., 25 Nov. 2017. Web. 16 Dec. 2020. <https:/ / youtu.be/PNxoAMRfkXc>;.

Magicbox Hindi. "Indian folktales 2. World folktales in Hindi. Magicbox Hindi." YouTube. N.p., 18 Jan. 2019. Web. 16 Dec. 2020. <https://youtu.be/zMXJZjxfEIo>;.

Magicbox hindi. "The clever Birbal moral stories akbar birbal tales. Hindi kahaniyan for kids." YouTube. N.p., 4 June 2019. Web. 16 Dec. 2020. <https:/ / youtu.be/fCUOrqWEFJ4>;

Mayowa, Alade S. "Development of a 2D animation for Yoruba Folktale Narrative." International Journal of Art, Culture and Design Technologies 9.1 (2020): 47-61. Web. 15 Dec. 2020.

$<$ https://www.researchgate.net/publication/342612926_Development_of_a_2D_Digital_Animation_for _Yoruba_Folktale_Narrative>;.

New comady mix. "Lubhiya byapari Assamese story collection moral stories in assamese." YouTube. N.p., 19 May 2020. Web. 7 Oct. 2020. <https:/ / youtu.be/5E5UWEurnxY>;.

New comady mix. "Lubhiya hadhu story collection moral stories in assamese." YouTube. N.p., 16 Mar. 2020. Web. 7 Oct. 2020. <https://youtu.be/P4-TcKL81po>;.

Parmar, Shyam. Traditional folk media in India. New Delhi: Geka Books New Delhi, 1975. Print.

Penjore, Dorji. "Folktales and education: Role of Bhutanese folktales in value transmission." Journal of Bhutan studies 2.1 (2005): 256-277. Web. 1 Oct. 2020.

<https://www.researchgate.net/publication/26519032_Folktales_and_Education_Role_of_Bhutanese_F olktales_in_Value_Transmission>;.

Propp, Vladimir. Theory and history of folklore. 5th ed. Minnesota: U of Minnesota Press, 1984. Pdf.

Shemaroo kids. "Bal Ganesh- Ganesh the elephant headed God." YouTube. N.p., 17 Aug. 2012. Web. 16 Dec. 2020. <https:/ / youtu.be/O-VeMx8YlyU>;.

Ssoftoons animation. "Jadur jata thakurmar jhuli. Fairy tales ssoftoons Bangla cartoon." YouTube. N.p., 1 Nov. 2018. Web. 16 Dec. 2020. <https:/ / youtu.be/vzk5m2xXP4Y>;.

Ssoftoons animation. "Panta buri thakurmar jhuli new story. Ssoftoons." YouTube. N.p., 15 June 2019. Web. 16 Dec. 2020. <https:/ / youtu.be/CbORQdWVSpw>;.

Ssoftoons animation. "Sonali maach story of thakurmar jhuli fairy tales in Bengali. Ssoftoons Bangla cartoon." YouTube. N.p., 19 July 2019. Web. 16 Dec. 2020. <https://youtu.be/EdIP4zODsfw>;. 
Toonskids Hindi. "Budhiya aur sher. Hindi kahaniyan. Bedtime moral stories. Hindi fairy tales." N.p., 16 Mar. 2020. Web. 16 Dec. 2020. <https://youtu.be/BZUUainSSPk>.

${ }^{1}$ Maya Bhowmick is a student of the Department of Communication and Journalism, Gauhati University, Guwahati. Presently, she is pursuing her post-graduation from the department.

${ }^{2}$ Ankuran Dutta is an Associate Professor and Head, Department of Communication and Journalism, Gauhati University, Guwahati, Assam, India. Dr Dutta is a media educator by profession with an experience of about 15 years and involved in different academic activities in India, Bangladesh, Canada, Maldives, Sri Lanka, Pakistan and Malaysia. He has been awarded with prestigious "National Award for Outstanding Efforts in Science and Technology Communication in the Electronic Medium, 2018" by the NCSTC, DST, Ministry of Science and Technology, Government of India on February 28, 2019. He is also awarded as the Best Media Educator (Associate Professor) at Media and Media Education Summit, 2018 in New Delhi. Dr. Dutta was nominated from India to participate in SUSI in Journalism and Media at E. W. Scripps School of Journalism at the University of Ohio, USA from June-August, 2018 and pursued a shortterm research at York University, Canada in 2011 as a Shastri Indo-Canadian Institute 